\title{
Cartas de Rubens Borba de Moraes ao livreiro português António Tavares de Carvalho
}

Marcos Antonio de Moraes ${ }^{I}$

$\mathrm{E}$ NTRE 1961 e 1985, o bibliófilo, bibliógrafo e professor de biblioteconomia Rubens Borba de Moraes (18991986) correspondeu-se com o "livreiro-antiquário” português António Tavares de Carvalho, à frente da Old Books and Prints, em Lisboa. O vínculo, inicialmente comercial, transfigura-se ao longo do tempo, adquirindo a feição de uma calorosa amizade, abrindo espaço nas cartas para uma boa "prosa-fiada" (p.338). As 228 mensagens assinadas pelo paulista distribuem-se irregularmente no período, adensando-se na década de 1960, mais espaçadas nos anos seguintes, sem perder o vigor afetivo da interação.

As Cartas de Rubens Borba de Moraes ao livreiro português António Tavares de Carvalho, organizadas pelo professor e editor Plínio Martins Filho (2018), a partir de cópia da documentação obtida pelo docente da ECA-USP Ivan Teixeira, falecido em 2013, recuperam a história dessa substanciosa interlocução, cuja importância reside não apenas em sua dimensão biográfica, ao lançar luz sobre o autor de $O$ bibliófilo aprendiz (1965), como também em termos culturais abrangentes. A sumária, mas apurada "apresentação" do organizador do volume, desenha um sugestivo mapa do "potencial informativo da documentação" (p.l). Em geral, correspondências de intelectuais constituem ricos universos discursivos que espelham linhas de força do pensamento de uma época, posturas ideológicas e ideários coletivos. Circulando no âmbito privado, visões pessoais expressas no calor da hora surgem menos controladas, passíveis de reformulações em face da reação do interlocutor. O currente calamo deixa frestas por onde passam até mesmo leviandades e preconceitos.

Rubens Borba de Moraes deixou marca significativa no campo letrado. Nome presente no movimento modernista de São Paulo na década de 1920, ligou-se à revista Klaxon; publicou Domingo dos séculos (1924), ensaio em defesa da arte de vanguarda. Reconhecido pelo seu pioneirismo na moderna operacionalização de acervos bibliográficos, esteve ao lado de Mário de Andrade no Departamento de Cultura, capitaneando a Biblioteca paulistana (1936-1942); na direção da Biblioteca Nacional do Rio de Janeiro (1945-1947); e ocupando postos prestigiosos na área de informação e de bibliotecas na Organização das Nações Unidas, em Nova York e Paris (1948-1958). Em 1958, publicou a incontornável Bibliographia brasiliana (Moraes, 2010), em inglês, em dois volumes, obra revista e ampliada em 1983 (e reeditada em 2010, em português, sob selo da Edusp/Fapesp); em 1969, tirou do prelo a Bibliografia brasileira do periodo colonial; em 1979, Livros e bibliotecas no Brasil colonial, entre outros títulos.

De António Tavares de Carvalho, contrariamente, restaram poucos traços biográficos em circulação. No prefácio da Bibliografia brasileira do periodo colonial, Rubens Borba de Moraes (1969) 
aquilata a contribuição do comerciante de livros raros e manuscritos que the atendia com dedicação: "Ficarei sempre grato ao meu amigo [...], pelo interesse que demonstrou por este trabalho e pela ajuda no enriquecimento de minha coleção particular, núcleo desta bibliografia" (p.XIX). Se a edição das Cartas não colige as mensagens do livreiro, na escrita epistolar do bibliófilo emerge a presença viva de seu interlocutor, desvelando uma personalidade que, diferentemente do que, talvez, se pudesse imaginar, não se move apenas pelo impulso pecuniário. Presentifica-se o homem culto que, em 1962, revela o propósito de "escrever [...] tese sobre a ordem de São Miguel" (p.81); e, em 1965, oferece seus préstimos intelectuais, logo aceito pelo bibliófilo:

Eu não sei o que lhe dizer sobre sua tão amável proposta de fazer-me as pesquisas das obras que ainda não vi para terminar a minha Bibliografia Luso-Brasileira. [...] eu não poderia encontrar outra pessoa mais capaz para esse trabalho que demanda conhecimento de livros antigos e uma cultura que nem toda gente tem. (p.210)

Rubens louva, nas cartas, a "capacidade "descobritiva" do negociante (p.93) empenhado em rastrear obras pelas quais ansiava. "Não há o que lhe peça que não descubra!", assegurou a seu destinatário em 1962, "devo-lhe muitas das melhores e mais raras peças de minha coleção de autores brasileiros antigos. É uma gentileza que não me esqueço que lhe devo" (p.93). Em suas "recordações", enquanto Testemunha ocular (Moraes, 2011), publicadas postumamente, ainda fixará o reconhecimento ao livreiro que lhe facultara a aquisição do primeiro livro impresso no Brasil, em 1747, no Rio de Janeiro, a Relação da entrada do bispo, do qual, na época, asseverava existir só "uns seis ou sete exemplares no mundo", o dele sendo o "único em mãos de particular" (p.234). Em 1974, ao fazer na carta um balanço de seu acervo, considerando a possibilidade de receber o amigo em sua residência em Bragança Paulista, constata "quantos exemplares" lhes vieram por intermédio dele: "Minha coleção deve-lhe muito! Espero que continue a enriquecê-la" (p.416).

As relações epistolares são indelevelmente movidas por interesses, sejam de ordem afetiva, intelectual, sejam econômicas. O diálogo travado entre um bibliófilo e um livreiro pressupõe um espectro de aspirações afins (expectativa de aquisição de uma obra versus expectativa de lucro), a abertura para margens de concessões no trato comercial, gestos de favorecimento (a lembrança de um determinado cliente e não de outro, por exemplo, ambos interessados pelo mesmo volume). Rubens Borba de Moraes, em face de Tavares de Carvalho, não regateia; julgava conservar as "boas virtudes burguesas", guardando ainda "horror a dívidas" (p.464). Pedir abatimento, para ele, em 1973, convoca escusas altivas: "não é do meu feitio pechinchar, você bem sabe, mas se fosse possível fazer-me um descontozinho... Desculpe-me a franqueza. Mas só faça o desconto se isso não lhe aborrecer e não tiver um americano endinheirado que queira o exemplar [...]" (p.407).

A figura do livreiro associa-se intimamente à do bibliófilo, em uma frutífera simbiose social. Rubens Borba de Moraes cumprirá, em $O$ bibliófilo aprendiz, o elogio ao negociante de livros, no capítulo "Livrarias e a arte de comprar". O autor parte da premissa de que "o livrei- 
ro é um comerciante, a livraria é sua casa de negócio" (p.29). Reconhece nele a figura de um "conselheiro útil" (p.31), se bem informado. A cumplicidade os une:

[...] todo bibliófilo anda à procura de um ou outro livro a vida inteira. [...] o livreiro amigo, o seu livreiro, pode prestar-lhe um serviço inestimável. Todo bom livreiro conhece sua freguesia, sabe exatamente o que cada um coleciona e procura. Aparecendo um exemplar do livro desejado, ele terá prazer em lhe oferecer em primeiro lugar. (p.30)

Para Moraes, o "bom livreiro é aquele que sabe comprar e vender pelo justo preço. Ladrão é aquele que vende um livro mais caro do que realmente vale" (p.29). Em outro capítulo da obra, registra os inúteis embates com certos vendedores, quando estes, sabedores dos anseios de seus clientes, majoram o preço das obras. Não há saída, no caso, pois ele sabia que "acabava pagando mesmo, com medo de perder a ocasião" (p.60). Ao livreiro "desonesto", restava o fim da "reputação" (p.33).

Nas cartas dirigidas a Tavares de Carvalho, Rubens Borba de Moraes reconhece que "os livreiros não são filantropos" e que "bons negócios são sempre recíprocos” (p.216). Para ele, "negócios são negócios e amigos à parte" (p.172). A crua formulação leva a reboque um pacto para que o fortalecimento dos laços de amizade não redunde em prejuízo à sua atividade de bibliófilo:

Sei que muitos dos livros que me cedeu teriam alcançado preço maior se os tivesse vendido a compradores ingleses e americanos. São atenções que não esqueço, creia. Mas se o amigo sente-se embaraçado em cobrar-me o lucro natural que qualquer amigo me cobraria então estou ameaçado de perder muito livro!! Santo Deus, não se sinta embaraçado porque quem sai perdendo sou eu!!” (p.218)

Em O bibliófilo aprendiz, Rubens Borba de Moraes caracteriza a atividade do colecionador de livros, ao assegurar que "a bibliofilia não é somente um passatempo de homens cultos", sendo também "um negócio" e uma "obra de benemerência" (p.16). Enquanto "passatempo", mobilizado pelo gosto da erudição, o amor aos livros deixa aflorar sentimentos lúdicos, na demanda firme de obras tão sonhadas. As listas de "desiderata” (p.50) nas missivas de Rubens estão sempre abertas, na multiplicação de desejos. "Para ser completamente feliz", escreve Rubens a Tavares de Carvalho, gracejando, em 1970, "precisava de três coisas: uma casa de campo, um cão chow-chow e a edição de Marília da Imprensa Régia do Rio de Janeiro. A casa tenho, o chow-chow vem para cá em janeiro quando voltar das férias. [...] Realizada essa terceira parte do meu sonho morrerei realizado!" (p.367). Essa edição "raríssima”, de 1810, aliás, "mais difícil encontrá-la do que a própria primeira edição de 1792" (p.418), como se lê na Bibliographia brasiliana, e da qual se sabia da existência de apenas quatro exemplares remanescentes, ele, contudo, nunca pudera ter o gosto de ver em suas estantes prodigiosamente bem fornidas.

A correspondência trocada com um livreiro pode realçar traços psicológicos de um bibliófilo. Este ama o que tem, mas igualmente o que lhe falta. Regozija-se ao ver em seu acervo uma obra a que seus pares tanto aspiram: "estou contentíssimo com essas [...] aquisições [...]", escreve Rubens Borba de Moraes, em 1964, ao amigo lusitano, "verifiquei que são rigorosamente inéditas e, 
esse fato, bastou-me para sentir o prazer egoísta dos bibliófilos quando possuem o que ninguém tem" (p.190). A posse dos livros "enche[-o] de alegria" (p.66). $\mathrm{O}$ escritor, alheio à religião, em suas cartas, com leveza brincalhona, traduz as ambições do colecionador emprestando termos condenáveis sob uma perspectiva cristã, associando-as aos pecados capitais da "gula" (p.77, 85, 200), da "vaidade" (p.117, 178, 305) e da "cobiça" (p.143). Lançando mão de imagem bíblica, mostra-se "aflito à espera desse maná que $[\ldots]$ cai do céu", não "pelas mãos de Jeová", mas das de seu providencial livreiro. Não resiste à "tentação" (p.207) em face de algumas ofertas, embora não fossem para ele prioritárias na ocasião. Imagina a proteção de um "anjo da guarda (que é bibliófilo)" (p.136) nas suas transações. Devota-se, como estudioso, ao estudo dos textos e da história deles; detém, ainda, o olhar lambareiro sobre a materialidade dos livros (o apuro estético das capas de época, a integridade dos papeis, os procedimentos tipográficos etc.). Em 1963, confessa: "tenho a paixão por encadernações [...] fiquei com água na boca com as de veludo que me promete. Tenho algumas" (p.123).

"Very excited" (p.216) em face de manuscritos e impressos antigos, Rubens Borba de Moraes vivencia a angústia da espera das encomendas, temendo por seus tesouros que atravessavam o Attântico em tantas mãos indistintas. Recalcitra, diante de atrasos postais, acusando, recorrentemente, a precariedade dos correios brasileiros, agravante de seus sofrimentos. "Essas delongas", explica em 1963, "põem-me louco de raiva e atrapalham-me a minha pacata vida de bibliófilo" (p.69). Perpassa, assim, pelas cartas, um sinistro leitmotiv, exibindo as vicissitudes na circulação epistolar do país. Desfia na conversa com o livreiro as mazelas desse órgão público: "o pior do mundo" (p.10), um pacote chegando a levar, em 1961, dois meses entre Lisboa e São Paulo, e sofrendo com a descuidada "brutalidade dos empregados" (p.12), correio "infame" (p.15), "pouco seguro" (p.23), irregular nas entregas domiciliares (p.49), "trapalhão" (p.135), "so expensive" na modalidade aérea (p.139), lento mesmo no uso de "registrados" (p.172), não confiável (p.152), enfim, um "inferno" (p.279). Promete ao destinatário, em alguma oportunidade, contar "as peripécias divertidas e dolorosas que [lhe] aconteceram com o correio no Brasil, livros considerados perdidos e achados milagrosamente" (p.215). Bem-humorado, Rubens pede ao livreiro, caso não encontrasse portador, que lhe enviasse livros pelo correio, não sem antes, em todo caso, rezar "três aves Marias" (p.264). Vê, em 1964, a imperícia dos correios como sendo "reflexo da situação política pavorosa" pela qual atravessava a sua terra (p.165).

As condições históricas, em particular, a desestabilização econômica do país, afiguram-se como sérios entraves na vida de um bibliófilo. O "passatempo" torna-se dificultoso ou mesmo inviável em tempos de crise financeira. Rubens e António testemunharam, na correspondência, extensa temporalidade da esfera política de suas pátrias. No Brasil, as cartas registram a renúncia de Jânio Quadros, as mudanças de governo, o golpe militar e a sua longa duração; em Portugal, referem-se à Revolução dos Cravos, em 1974, que colocava fim ao governo autoritário de Salazar. As posições tomadas pelos missivistas diante desses eventos desvelam ideologias de 
classe e os limites de compreensão da realidade social, espelhando acomodações conservadoras e reformulações críticas do pensamento (um tópico fecundo a ser extensamente explorado a partir desta correspondência). Em 1969, o paulista formula a sua queixa acerca da "interferência do governo entre dois amigos que vendem e compram livros" (p.337). As intromissões se cumprem em razão das instabilidades cambiais, ou por força do rígido controle de montantes enviados para o exterior, assim como pela "censura secreta" nos envelopes, sob o regime ditatorial, para fiscalizar "depósitos bancários no exterior” (p.268). Nos anos 1980, aquisições de livros são inviabilizadas. Explica-se Rubens em 1981, noticiando a "inflação de 100\%" e a crise econômica geral: "eu, como sabe, nada compro. Os preços modernos não são reais para intelectuais aposentados" (p.476). Para ele, resta o bordão, com algumas variações, pontuando nas mensagens o desgosto de existir em um "país subdesenvolvido" (p.134, 169, 287, $315,334,397)$ : "muito sofre o brasileiro!" (p.316) ou "muito sofre o bibliófilo brasileiro!” (p.243).

"Para que vale dinheiro senão para se gastar naquilo que dá prazer?” (p.330), indaga Rubens Borba de Moraes em carta de 1969. A bibliofilia, como ele mesmo estimava, é um "negócio", mas, evidentemente, não apenas entre livreiro e colecionador, como também entre bibliófilos. Os livros raros trocam de endereço ao sabor dos (des)interesses dos colecionadores. O empenho e o prazer na aquisição de uma obra não significam o ponto final de sua deriva na rede do colecionismo. As "diretrizes" que orientam as aquisições de livros modificam-se. Rubens anuncia a Tavares de Carvalho, em
1966: "resolvi vender uma parte de minha biblioteca: os livros sobre o Brasil". Ficaria apenas "com as obras de autores brasileiros, as primeiras impressões feitas no Brasil $[\ldots]$ e as encadernações brasonadas brasileiras" (p.247), devotando-a a aumentá-la. Esses livros seguiriam para as estantes privilegiadas de outro bibliófilo, José Mindlin, o que agradava muito a Rubens, ponderando que o amigo ficaria "com a melhor Brasiliana que existe no país e tem os capitais para completá-la" (p.250). Em 1974, vende ao mesmo bibliófilo outra porção de obras raras, primeiras edições de "autores brasileiros do século XIX", 1.200 volumes, que dizia ter reunido "sem fervor" (p.416). Firma, na ocasião, seu desígnio de robustecer o conjunto de "livros de autores brasileiros do período colonial" e o das "primeiras impressões brasileiras, de 1808 a 1822" e “ 'alguna cosita más', quando valer a pena!!!” (p.416).

Após a morte de Rubens Borba de Moraes, também essa parcela de livros, 1.700, por disposição testamentária, seguiria para o acervo de Mindlin. Informa Briquet de Lemos: "Com esse legado e as duas coleções vendidas a José Mindlin [...] mais os livros reunidos por este, se formaria a 'Biblioteca [Brasiliana Guita e] José Mindlin'" (Moraes, 2011, p.240), atualmente aberta à consulta pública no Espaço Brasiliana da Universidade de São Paulo. Nesse sentido, a matéria bibliográfica para o gozo individual de seus detentores (coleção pessoal), conquistada com tanto empenho, paixão e alto dispêndio, como evidenciam as Cartas de Rubens Borba de Moraes ao livreiro português António Tavares de Carvalho, transmuta-se em importante "obra de benemerência", na realização da partilha democrática das 
raízes da cultura letrada brasileira (legado coletivo). Compreende-se bem, agora, o apelo de Rubens a Tavares de Carvalho, na carta de junho de 1962, a respeito de uma obra rara que muito desejava: "lembre-se por amor deste bibliógrafo e para o bem-estar das letras brasileiras" (p.61).

\section{Referências}

MARTINS FILHO, P. (Org.) Cartas de Rubens Borba de Moraes ao livreiro português António Tavares de Carvalho. São Paulo: Biblioteca Brasiliana Guita e José Mindlin, 2018.

MORAES, Rubens Borba de. Bibliografia brasileira do período colonial. São Paulo: IEB, 1969.

. O bibliófilo aprendiz. 3.ed. Brasília: Briquet de Lemos/Casa da Palavra, 1998.

Bibliographia brasiliana: livros raros sobre o Brasil publicados desde 1504 até 1900 e obras de autores brasileiros do período colonial. Tradução Correia. [ $l^{\text {a }}$ edição brasileira, traduzida da 2.ed. ampl. e com base no exemplar do autor]. São Paulo: Edusp; Fapesp, 2010.

Testemunha ocular (recorda-

ções). Brasília: Briquet de Lemos, 2011.

Marcos Antonio de Moraes é professor do Instituto de Estudos Brasileiros Universidade de São Paulo. Bolsista de Produtividade em Pesquisa, CNPq.

@-mamoraes@usp.br

https://orcid.org/0000-0001-7127-9254

Recebido em 2.10.2018 e aceito em 5.11 .2018

I Instituto de Estudos Brasileiros, Universidade de São Paulo, São Paulo, São Paulo, Brasil. 